\title{
Computational study of the proton affinity and basicity of structurally diverse $\alpha_{1}$-adrenoceptor ligands
}

\author{
C. Matijssen ${ }^{\text {a }}$, G. K. Kinsella ${ }^{b}$, G. W. Watson ${ }^{a}$ and I. Rozas ${ }^{a_{*}}$
}

\begin{abstract}
The $\alpha_{1}$-adrenoceptor is a target for the treatment of several conditions from hypertension to benign prostatic hyperplasia. In this paper, we describe a new analysis approach to explore the conformational space of several ligands of the $\alpha_{1}$-adrenoceptor and we also present the calculation of their proton affinity and basicity. For each compound a conformational search followed by a semi-empirical optimisation was performed and a selection of conformations for each ligand was subjected to further optimisation using density functional theory methods. Different positions were explored to determine the favoured site of protonation, and then, the proton affinity (in the gas phase) and basicity (using the polarisable continuum model for the aqueous solution) were calculated for each of them. In addition, an alternative method using one explicit water molecule in combination with the polarisable continuum model for aqueous solvent was explored. Moreover, the acid dissociation constant ( $\mathrm{p} K_{\mathrm{a}}$ ) in water of these 26 compounds was calculated because this is an important parameter for a ligand when binding to its receptor. The experimental $\mathrm{p} K_{\mathrm{a}}$ values of six of these ligands and those of two compounds with a very low and a very large $\mathrm{p} K_{\mathrm{a}}$ were used to validate the theoretical methodology. Copyright $\odot 2011$ John Wiley \& Sons, Ltd.
\end{abstract}

Keywords: acid dissociation constant; $\alpha_{1}$-adrenoceptor; basicity; polarisable continuum model; proton affinity

\section{INTRODUCTION}

Drugs interact with their receptor in an aqueous environment and at physiological $\mathrm{pH}$. Therefore, their protonation state plays an important role in the interaction between the ligand and the receptor. In particular, looking at drugs that interact with $\alpha_{1}$-adrenoceptors ( $\alpha_{1}$-ARs), which are $G$ protein coupled receptors (GPCRs) involved in several diseases and conditions, ${ }^{[1]}$ it has been found that a protonated $\mathrm{N}$ atom plays an important role in the binding of the ligands to a particular $\alpha_{1}$-AR subtype $\left(\alpha_{1 A}-A R\right)$. This protonated $\mathrm{N}$ has become a common feature in several pharmacophore models; ${ }^{[2-5]}$ and thus, in docking studies, it has been shown that an aspartic acid (conserved amongst most of the GPCRs) can interact with this protonated functional group. ${ }^{[6]}$

The preference for each $\mathrm{N}$ atom to be protonated can be determined by calculating the corresponding basicity (i.e. proton affinity in the gas phase-PA-). Techniques such as electrospray ionization, matrix-assisted laser desorption or the extended kinetic method allow for the experimental determination of $\mathrm{PA}_{i}^{[7,8]}$ however, basicities can also be determined using computational methods. To obtain accurate PA values in the gas phase, or basicities (B) in solvation, the bioactive or, when this is not known, some of the most stable conformers for each compound should be considered. Hence, a conformational search can be performed followed by a thorough optimisation of a large number of possible conformations. This step is time consuming and often simplified by limiting the number of conformations that are optimised. However, the correct minimum energy conformation should contribute to a better description of molecular properties participating in the ligand-receptor interactions and, for that reason, we have chosen an approach that selects a number of low energy conformations based on ligand structural flexibility and allows further refinement of each conformation. From the collection of optimised conformers, the minimum energy conformation can be selected. This minimum energy structure can then be used for $\mathrm{PA} / \mathrm{B}$ determination searching for the most favourable $\mathrm{N}$ atom to be protonated.

Using density functional theory (DFT) methods, Alkorta et al. have previously studied the basicity of a number of hydrogen bonded complexes between halogen acids and different bases, $^{[9]}$ and that of different triple bonded molecules formed by $\mathrm{C}, \mathrm{N}, \mathrm{Si}, \mathrm{P}, \mathrm{B}$ and $\mathrm{Al} .{ }^{[10]}$ Also, Alkorta and colleagues have calculated the PA of different series of hydrocarbons, ${ }^{[11]}$ triazoles, ${ }^{[12]}$ and small molecules. ${ }^{[13]}$ Moreover, Dmitrenko et al. obtained PAs within $3-5 \mathrm{kcal} \mathrm{mol}^{-1}$ of the experimental values in a series of small molecules (enolate intermediates and phosphine complexes). ${ }^{[14,15]}$ To mimic the solvent, different approaches can be used but we have previously found that the use of the polarisable continuum model (PCM) produces good results. ${ }^{[16,17]}$

Thus, using the energy of the minimum energy conformation, the PA (enthalpies in the gas phase) or the basicity (free energies in the solvated phase, PCM) for each of the $\mathrm{N}$ atoms can be determined using formula (1) or (2) respectively

\footnotetext{
* Correspondence to: I. Rozas, School of Chemistry, University of Dublin, Trinity College, Dublin 2, Ireland.

E-mail: rozasi@tcd.ie

a C. Matijssen, G. W. Watson, I. Rozas

School of Chemistry, University of Dublin, Trinity College, Dublin 2, Ireland

b G. K. Kinsella

Department of Biology, National University of Ireland, Maynooth, Co. Kildare, Ireland
} 


$$
\text { (gas phase) } P A=E_{\text {protonated }}-E_{\text {unprotonated }}
$$

$$
(\mathrm{PCM}) \mathrm{B}=\mathrm{E}_{\text {protonated }}-\mathrm{E}_{\text {unprotonated }}-\mathrm{E}\left(\mathrm{H}^{+}\right)
$$

where $E_{\text {protonated }} / E_{\text {unprotonated }}$ are the energies of the protonated and unprotonated species (enthalpies in the gas phase or free energies in the $\mathrm{PCM}), \mathrm{E}\left(\mathrm{H}^{+}\right)$would be null in gas phase, but in the PCM is the solvation free energy of the proton $\left[\Delta G_{\text {solv }}^{0}\left(H^{+}\right)\right]$, which has been experimentally determined in water as -265.9 kcal mol ${ }^{-1}[18,19]$

As mentioned before, the basicity and hence the $p K_{\mathrm{a}}$ plays an important role in the pharmacokinetic profile of a potential drug. The experimental evaluation of the $\mathrm{p} K_{\mathrm{a}}$ of a compound is not always possible and can be tedious. However, the $\mathrm{p} K_{\mathrm{a}}$ in water can also be determined using a computational approach based on the thermodynamic cycle shown in Fig. 1. ${ }^{[7,20-22]}$

After calculation of the minimum energy of the molecule in the different protonation states, the $\mathrm{p} K_{\mathrm{a}}$ in water can then be derived from this thermodynamic cycle using formula (3)

$$
p K_{\mathrm{a}}=\frac{\Delta G_{\mathrm{aq}}^{0}}{2.303 \times R T}
$$

where $\Delta G_{\mathrm{aq}}^{0}$ is the aqueous solvation free energy, $R$ is the universal gas constant and $T$ is the temperature $(298 \mathrm{~K}) . \Delta G_{\mathrm{aq}}^{0}$ can be calculated using formula (4)

$$
\Delta G_{\text {aq }}^{0}=\Delta G_{\text {gas }}^{0}-\Delta G_{\text {solv }}^{0}\left(\mathrm{AH}^{+}\right)+\Delta G_{\text {solv }}^{0}(\mathrm{~A})+\Delta G_{\text {solv }}^{0}\left(\mathrm{H}^{+}\right)
$$

The $\Delta G_{\text {solv }}^{0}(A)$ and $\Delta G_{\text {solv }}^{0}\left(\mathrm{AH}^{+}\right)$terms can be obtained from our calculations by subtracting the gas-phase free energy from the PCM free energy. The $\Delta G_{\text {solv }}^{0}\left(\mathrm{H}^{+}\right)$term, as mentioned before, is a known experimental value. ${ }^{[13,14]}$ The $\Delta G_{\text {gas }}^{0}$ term can be obtained using formula (5)

$$
\Delta G_{\text {gas }}^{0}=G_{\text {gas }}^{0}(\mathrm{~A})+G_{\text {gas }}^{0}\left(\mathrm{H}^{+}\right)-G_{\text {gas }}^{0}\left(\mathrm{AH}^{+}\right)
$$

where $G_{\text {gas }}^{0}\left(\mathrm{AH}^{+}\right)$and $G_{\text {gas }}^{0}(\mathrm{~A})$ are the free energy of the protonated and unprotonated states respectively. $G_{\text {gas }}^{0}\left(\mathrm{H}^{+}\right)$is the free energy of the proton and can be calculated using the Sackur-Tetrode equation resulting in $-6.28 \mathrm{kcal} \mathrm{mol}^{-1} \cdot{ }^{[23]}$ Hence, knowing the free energy of all the solvated species $\left(\mathrm{A}\right.$ and $\left.\mathrm{AH}^{+}\right)$calculated with PCM we can calculate $\Delta G_{\mathrm{aq}}^{0}$ and determine the $\mathrm{p} K_{\mathrm{a}}$ of the compounds.

Therefore, the aim of this study is to explore the conformational space of several $\alpha_{1}$-AR's ligands and to theoretically calculate their $\mathrm{PA}$, basicity and $\mathrm{p} K_{\mathrm{a}}$ to determine their optimal protonated state for future molecular modelling and docking studies.

\section{METHODS}

The agonists adrenaline and noradrenaline and a selection of $\alpha_{1}$-AR antagonists taken from the literature ${ }^{[2]}$ resulted in a set

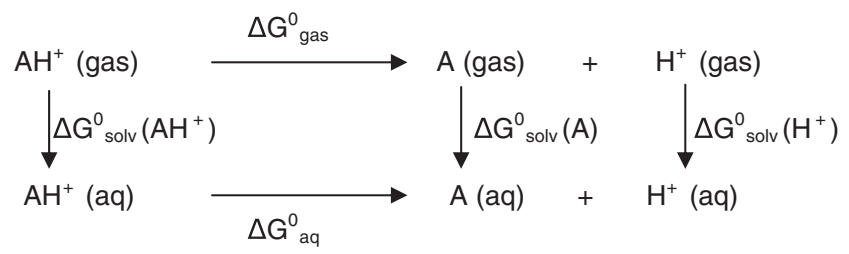

Figure 1. Thermodynamic cycle of a compound in gas and solvent states describing the energy terms which arise from the change from one state to another. of 26 compounds (Fig. 2) covering a wide range of binding affinities for the different $\alpha_{1}$-ARs subtypes. Considering that the experimental $\mathrm{p} K_{\mathrm{a}}$ value of adrenaline $(\mathbf{1})_{,}^{[24]}$ noradrenaline (2), ${ }^{[25]}$ prazosin (3), ${ }^{[26]}$ alfuzosin $(4),{ }^{[27]}$ doxazosin $(5)^{[28]}$ and terazosin $(\mathbf{6})^{[29]}$ are already known, these compounds will serve as a validation set for the determination of the computational $\mathrm{p} K_{\mathrm{a}}$ values presented here.

These compounds were subdivided into six different groups based on common scaffolds (Fig. 3) and thus, this common substructure will be used to derive the site of protonation for similar ligands.

To explore the conformational space of these molecules, a random search using the Monte Carlo method was performed with SYBYL (version 7.2, Tripos International, St. Louis, MO, USA $)^{[30]}$ applying the conjugate gradient minimisation method, a maximum number of iterations of 1000 , a gradient of 0.0005 , the Tripos force-field and Gasteiger-Hückel charges. This conformational search produced 200-1500 different conformations for each compound. Each conformer was further optimised using GAUSSIAN03 (Gaussian, Inc., Wallingford, CT, USA) ${ }^{[31]}$ with the AM1 semi-empirical method, and the energy and various dihedral angles were used to select different conformations.

Taking into account the number of dihedral angles that could account for molecule flexibility, two different approaches were used to select the most representative conformations for further optimisation: (i) in the case of molecules with $\leq 5$ rotatable bonds, the corresponding dihedrals of each possible pair of rotatable bonds were plotted against each other. Considering that each rotatable bond of the AM1-optimised structures produced two, four, six or eight possible dihedral angles, different clusters were formed. From each cluster the lowest energy conformation was selected; (ii) in the case of molecules with $>5$ rotatable bonds, an alternative approach was used. Thus, the dihedral angle for each rotatable bond was plotted against the conformer's energy and in that way several clusters of two to eight angles were formed. From each cluster the conformation with the lowest energy was selected.

Using either of these methods for the selection of low energy conformations produced a smaller set of 10-25 conformations per compound. Each of these AM1 conformations was further optimised with GAUSSIANO3 using the Becke 3-Parameter (Exchange), Lee, Yang and Parr (B3LYP) hybrid method with the 6-31 $\mathrm{G}^{*}$ basis set. From the different optimised conformers, that with the lowest electronic energy was selected.

To determine the PA, each of the $\mathrm{N}$ atoms of each structure was individually protonated. Optimisation of the neutral and the different protonated conformations was performed using B3LYP/6-31 G* level of theory in the gas phase and in the PCM solvent model. Additionally, vibrational frequency calculations were performed at the B3LYP/6-31 G* level, to characterise the stationary points as minima. The variation in zero-point energies (ZPE) and thermal corrections from zero degree to $298 \mathrm{~K}$ have been considered in the calculations. No scaling factor for the ZPE values was taken into account.

An alternative strategy to account for the solvation effects was pursued by adding one explicit water molecule ${ }^{[32,33]}$ interacting through hydrogen bonds ( $\mathrm{HBs}$ ) with the structures considered (Fig. 4). We considered that an explicit water molecule would have a different effect on the compounds than a continuous solvation model such as PCM. Thus, we explored if different minimum energy conformations were found and, perhaps, more accurate $\mathrm{p} K_{\mathrm{a}}$ values. For the unprotonated state of each molecule, the $\mathrm{H}$ atom of the water molecule was orientated towards each of the 


\section{Adrenaline}

(1)
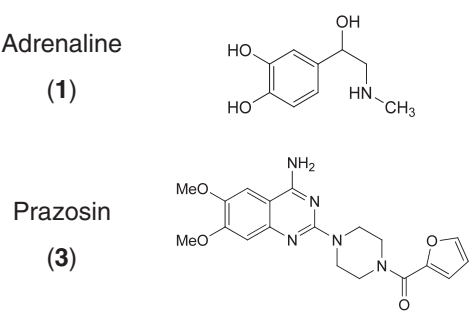

Doxazosin

(5)

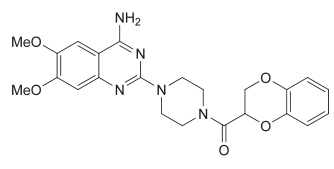

Cyclazosin

(7)

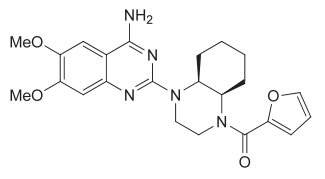

REC-15/2615

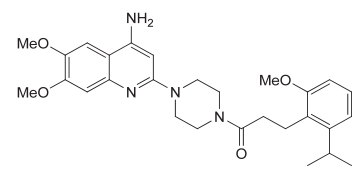

(9)

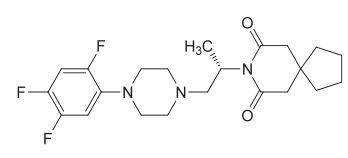

(11)

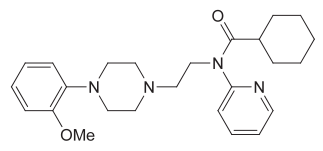

(13)

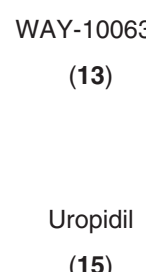

(15)

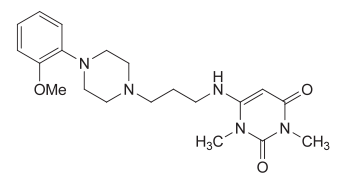

SKF-104856

(17)

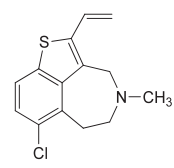

WB-4101

(19)

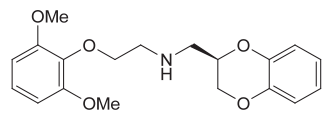

Benzoxathian

(21)

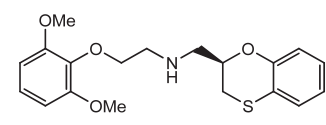

JHT-601

(23)

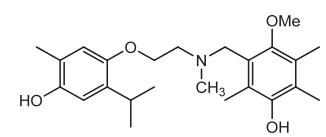

Indoramin

(25)

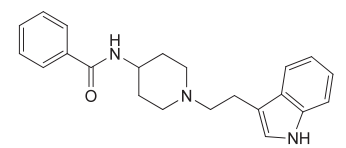

Noradrenaline

(2)

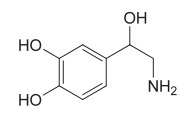

Alfuzosin

(4)

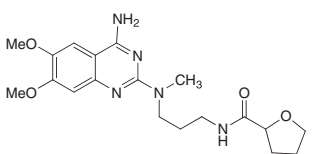

Terazosin

(6)

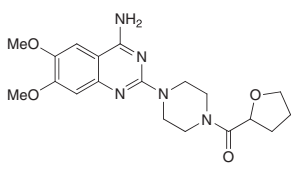

Abanoquil

(8)

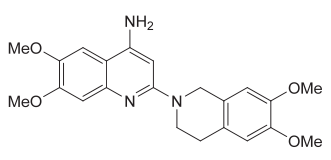

BMY-7378

(10)

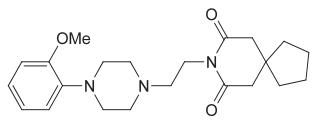

NAN-190

(12)

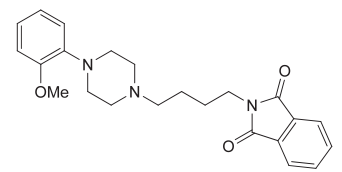

RS-100,975

(14)

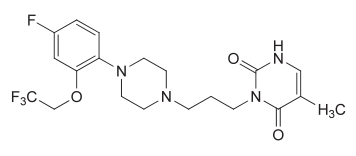

Phentolamine

(16)<smiles>Cc1ccc(N(CC2=NC3CCC2C3)c2cccc(O)c2)cc1</smiles>

Corynanthine

(18)

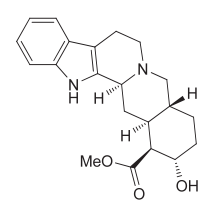

KMD-3213

(20)

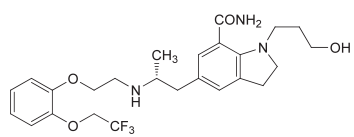

RS-17053

(22)

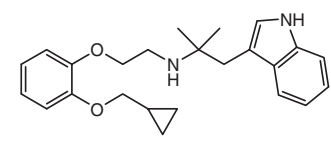

Spiperone

(24)

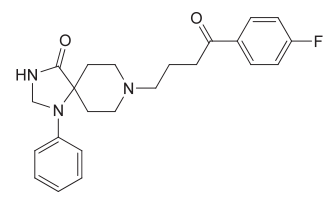

SNAP-1069

(26)

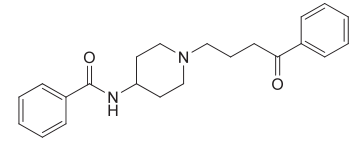

Figure 2. Structures of the 26 compounds studied in this work. 
<smiles>N#CC(O)c1ccc(O)c(O)c1</smiles>

Group 1<smiles>NC(=O)N(C=O)N=NN1CCN([Al])CC1</smiles>

Group 3<smiles>[R]Oc1ccccc1OCCNCC[N+](=O)[O-]</smiles>

Group 5<smiles>CC(C)N1CCN(c2nc(N)c3ccccc3n2)CC1</smiles>

Group 2<smiles>CN(C)CC1NCCN1</smiles>

Group 4

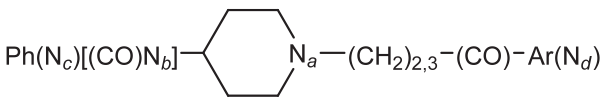

Group 6

Figure 3. Different scaffolds considered: Group 1 (compounds 1 and 2), Group 2 (compounds 3 to 9), Group 3 (compounds 10 to 15), Group 4 (compounds 16 to 18), Group 5 (compounds 19 to 23) and Group 6 (compounds 24 to 26). The N atoms to be protonated are indicated with subindex letters for each group.<smiles>Cc1nc2ccccc2c(C)[n+]1C=O</smiles><smiles>Cc1nc2ccccc2c(C)[n+]1O</smiles>

Figure 4. Examples of water molecule orientation and initial distance used (in $\AA$ ) in the complexes with the neutral (left) and protonated states (right).

$\mathrm{N}$ atoms at an initial distance of $2.0 \AA$. For the protonated form, the $\mathrm{O}$ atom of the water molecule was orientated towards the $\mathrm{H}$ atom protonating each $\mathrm{N}$ atom with a distance of 1.8 Á between both atoms as the starting point for the optimisation.

The computation of the ligands with an explicit water molecule in the gas phase and PCM will help to decide if such 'supermolecule' (ligand $+\mathrm{H}_{2} \mathrm{O}$ ) facilitates the computation of PA and basicity or, on the contrary, will not provide a better description only adding more computational time.

\section{RESULTS AND DISCUSSION}

\section{Determination of proton affinities and basicities}

The PA for each compound was calculated as the difference in enthalpy between the neutral and protonated species in the gas phase Eqn (1) whereas when using aqueous salvation, the basicities were calculated using the free energies including the solvation energy of the proton Eqn (2). The natural agonists adrenaline (1) and noradrenaline (2) only have one $\mathrm{N}$ atom that can be protonated; therefore, only one PA/B for each of the structures was calculated (Table 1). Comparing the $298 \mathrm{~K}$ thermally corrected structures with the uncorrected ones, both in the gas phase and the PCM solvent optimised structures, a decrease of the PAs $\left(\sim 9 \mathrm{kcal} \mathrm{mol}^{-1}\right)$ is observed. The difference between the gas phase optimisations and PCM optimisations is $\sim 213 \mathrm{kcal} \mathrm{mol}^{-1}$ for adrenaline and $\sim 209 \mathrm{kcal} \mathrm{mol}^{-1}$ for noradrenaline. These differences account for the solvation of the proton $\left(-265.9 \mathrm{kcal} \mathrm{mol}^{-1}\right)$ and other interactions that the molecule and
Table 1. Calculated proton affinities and basicities $\left(\mathrm{kcal} \mathrm{mol}^{-1}\right)$ of Group 1 compounds

\begin{tabular}{|llccccc|}
\hline & & & & & \\
& Nitrogen & $\mathrm{PA}$ & $\mathrm{PA}$ & $\mathrm{B}$ & $\mathrm{B}$ \\
& & $(0 \mathrm{~K})$ & $(298 \mathrm{~K})$ & $(0 \mathrm{~K})$ & $(298 \mathrm{~K})$ \\
\hline Adrenaline (1) & $\mathrm{N}_{a}$ & 241.5 & 232.5 & 28.2 & 19.5 \\
Noradrenaline (2) & $\mathrm{N}_{a}$ & 236.4 & 227.5 & 27.6 & 18.6 \\
\hline
\end{tabular}

the proton will establish with the environment in the aqueous solution model.

The results for Group 2 (compounds 3 to 9) are shown in Table 2. A similar PA/B pattern is observed for all the compounds within this set and the previous one, with the $\mathrm{N}_{c}$ atom being favoured for protonation. Nitrogen $\mathrm{N}_{e}$, in compounds 3-7 and 9, belongs to an amide group and, therefore, would not be likely protonated; while $\mathrm{N}_{a}$ is an 'aniline' type of amine and it would require very acidic conditions to be protonated. Accordingly, the PA/B values obtained for those $\mathrm{N}$ atoms were very low and are omitted from the table. Again the basicities (PCM results in aqueous soluition) are smaller than the gas phase PA. In articular, the $\mathrm{B}$ thermally corrected values obtained for $\mathrm{N}_{d}$ are so small (even negative in the case of compound 4) that it seems to indicate that this $\mathrm{N}$ would not be protonated at physiological conditions. Interestingly, $\mathrm{N}_{d}$ is not part of a six-membered ring (piperazine or piperidine) only in compound 4.

All compounds in Group 3 (10 to 15), which are favourably protonated at $\mathrm{N}_{b}$ in the gas phase (Table 3), have a $\mathrm{N}$ atom as part of an amide group $\left(\mathrm{N}_{d}\right)$ and because this type of $\mathrm{N}$ atom is rarely protonated the $\mathrm{PA} / \mathrm{Bs}$ obtained were very low and they 
Table 2. Calculated proton affinities and basicities $\left(\mathrm{kcal} \mathrm{mol}^{-1}\right)$ of Group 2 compounds

\begin{tabular}{|c|c|c|c|c|c|}
\hline & \multirow[b]{2}{*}{ Nitrogen } & \multicolumn{2}{|c|}{ Gas phase } & \multicolumn{2}{|c|}{ PCM (water) } \\
\hline & & PA (0 K) & PA $(298 \mathrm{~K})$ & B (O K) & B (298 K) \\
\hline \multirow[t]{3}{*}{3} & $\mathrm{~N}_{b}$ & 243.7 & 236.6 & 20.0 & 13.4 \\
\hline & $\mathrm{N}_{C}$ & 255.6 & 247.3 & 26.5 & 18.3 \\
\hline & $\mathrm{N}_{d}$ & 242.7 & 234.6 & 14.1 & 4.8 \\
\hline \multirow[t]{3}{*}{4} & $\mathrm{~N}_{b}$ & 259.6 & 250.4 & 19.9 & 10.0 \\
\hline & $\mathrm{N}_{C}$ & 264.7 & 256.0 & 27.0 & 17.6 \\
\hline & $\mathrm{N}_{d}$ & 253.2 & 244.9 & 10.6 & -0.1 \\
\hline \multirow[t]{3}{*}{5} & $\mathrm{~N}_{b}$ & 241.9 & 235.1 & 19.7 & 10.9 \\
\hline & $\mathrm{N}_{C}$ & 253.2 & 245.9 & 26.2 & 17.0 \\
\hline & $\mathrm{N}_{d}$ & 240.1 & 232.4 & 13.4 & 3.7 \\
\hline \multirow[t]{3}{*}{6} & $\mathrm{~N}_{b}$ & 244.9 & 237.5 & 20.1 & 9.6 \\
\hline & $\mathrm{N}_{C}$ & 256.0 & 248.0 & 26.6 & 17.4 \\
\hline & $\mathrm{N}_{d}$ & 243.5 & 234.9 & 14.4 & 2.6 \\
\hline \multirow[t]{3}{*}{7} & $\mathrm{~N}_{b}$ & 248.1 & 241.0 & 21.2 & 12.7 \\
\hline & $\mathrm{N}_{C}$ & 256.5 & 249.1 & 27.5 & 18.5 \\
\hline & $\mathrm{N}_{d}$ & 247.4 & 239.8 & 15.2 & 4.3 \\
\hline \multirow[t]{2}{*}{8} & $\mathrm{~N}_{C}$ & 261.1 & 253.6 & 30.1 & 22.4 \\
\hline & $\mathrm{N}_{d}$ & 249.0 & 241.3 & 18.8 & 8.4 \\
\hline \multirow[t]{2}{*}{9} & $\mathrm{~N}_{C}$ & 257.6 & 250.6 & 29.9 & 22.9 \\
\hline & $\mathrm{N}_{d}$ & 240.3 & 233.0 & 15.0 & 5.6 \\
\hline
\end{tabular}

are not shown in the table. The $\mathrm{N}_{b}$ position corresponds to a piperazine $\mathrm{N}$ atom attached to an aliphatic chain. Compound 11, which is the only derivative with a methyl branch in the aliphatic chain, seems to have a different PA/B pattern with slightly lower values than the rest of the compounds in the set. Compound $\mathbf{1 5}$ has another amino group, $\mathrm{N}_{c}$, which is an aniline type of nitrogen, which could explain the negative thermally corrected $B$ value obtained (see Table 3 ).

Compounds in Group 4 (16-18) show a consistent preference of protonation at nitrogen $\mathrm{N}_{a}$ in both the gas phase and aqueous PCM (Table 4). Compound $\mathbf{1 6}$ has other $\mathrm{N}$ atoms but differences larger than $20 \mathrm{kcal} \mathrm{mol}^{-1}$ are observed in favour of nitrogen $\mathrm{N}_{a}$ which seems logical considering that $\mathrm{N}_{b}$ and $\mathrm{N}_{c}$ are involved in an imidazoline ring. Compound $\mathbf{1 7}$ has only one $\mathrm{N}$ atom that can be protonated. In compound $\mathbf{1 8}$, the $\mathrm{N}_{c}$ belongs to an indole system and therefore is too acidic to be likely protonated (data not included in Table 4). Despite the limited number of compounds in this group and only two of them having multiple $\mathrm{N}$ atoms to be protonated, the large difference in PA/B observed indicates that nitrogen $\mathrm{N}_{a}$ is the one that will be protonated.

Compounds in Group 5 (19-23) show consistent results both in gas phase and PCM, all of them showing a preference for protonation at nitrogen $\mathrm{Na}$ (Table 5). Compounds 19, 21 and 23 have only one $\mathrm{N}$ atom that can be protonated. Compound 22 has two $\mathrm{N}$ atoms but $\mathrm{N}_{b}$ belongs to an indole system, hence, it is too acidic to be protonated. In the case of compound 20, a large difference favouring protonation on $\mathrm{N}_{a}$ over $\mathrm{N}_{b}$ (with a certain indole-like nature) is observed and $\mathrm{N}_{c}$ (amide) is too acidic to be likely protonated, for that reason the corresponding results are not included in the table.

The structures in Group 6 (24-26) show consistent results in both gas phase and PCM with a preference for protonation on the $\mathrm{N}_{a}$ atom (Table 6). In compound $\mathbf{2 4}$, there is a large difference in PA/B between nitrogen $\mathrm{N}_{a}$ and other $\mathrm{N}$ atoms (amide and aniline type); hence, nitrogen $\mathrm{N}_{a}$ is the preferred site for protonation. Nitrogen atom $\mathrm{N}_{b}$ belongs to an amide group (in 24 and 25) and $\mathrm{N}_{d}$ belongs to an indole ring (in 26), hence they are too acidic to be protonated.

The values of the PA/Bs obtained in each group of ligands have allowed us to identify which $\mathrm{N}$ atom is most likely to be protonated. Our results show that, in structurally similar compounds, as expected, the same $\mathrm{N}$ atom is preferred for protonation, which is useful when modelling the receptormolecule interaction in series of similar compounds.

\section{Modelling the solvent with the addition of an explicit molecule of water}

An alternative approach for the calculation of basicities in solvated molecules was taken by introducing a properly orientated water 


\begin{tabular}{|c|c|c|c|c|c|}
\hline & \multirow[b]{2}{*}{ Nitrogen } & \multicolumn{2}{|c|}{ Gas phase } & \multicolumn{2}{|c|}{ PCM (water) } \\
\hline & & PA (O K) & PA $(298 K)$ & B (O K) & B $(298 K)$ \\
\hline \multirow[t]{2}{*}{10} & $\mathrm{~N}_{a}$ & 250.0 & 240.6 & 22.8 & 12.8 \\
\hline & $\mathrm{N}_{b}$ & 252.4 & 244.5 & 23.6 & 14.9 \\
\hline \multirow[t]{2}{*}{11} & $\mathrm{~N}_{a}$ & 236.6 & 238.2 & 14.7 & 5.3 \\
\hline & $\mathrm{N}_{b}$ & 246.7 & 238.2 & 19.3 & 12.0 \\
\hline \multirow[t]{2}{*}{12} & $\mathrm{~N}_{a}$ & 248.9 & 239.4 & 22.9 & 15.6 \\
\hline & $\mathrm{N}_{b}$ & 251.1 & 242.5 & 27.4 & 16.6 \\
\hline \multirow[t]{3}{*}{13} & $\mathrm{~N}_{a}$ & 252.0 & 242.1 & 22.6 & 11.6 \\
\hline & $\mathrm{N}_{b}$ & 252.9 & 243.6 & 25.4 & 15.5 \\
\hline & $\mathrm{N}_{e}$ & 236.6 & 228.2 & 14.9 & 5.3 \\
\hline \multirow[t]{2}{*}{14} & $\mathrm{~N}_{a}$ & 246.8 & 236.5 & 17.2 & 8.5 \\
\hline & $\mathrm{N}_{b}$ & 247.9 & 237.9 & 27.2 & 17.2 \\
\hline \multirow[t]{3}{*}{15} & $\mathrm{~N}_{a}$ & 245.6 & 236.1 & 22.3 & 11.9 \\
\hline & $\mathrm{N}_{b}$ & 250.1 & 240.4 & 23.2 & 13.0 \\
\hline & $\mathrm{N}_{C}$ & 244.2 & 233.0 & 2.3 & -7.2 \\
\hline
\end{tabular}

\begin{tabular}{|c|c|c|c|c|c|}
\hline & \multirow[b]{2}{*}{ Nitrogen } & \multicolumn{2}{|c|}{ Gas phase } & \multicolumn{2}{|c|}{ PCM (water) } \\
\hline & & PA (0 K) & PA (298 K) & B (O K) & B $(298 \mathrm{~K})$ \\
\hline \multirow[t]{3}{*}{16} & $\mathrm{~N}_{a}$ & 251.4 & 243.8 & 11.5 & 2.4 \\
\hline & $\mathrm{N}_{b}$ & 233.0 & 224.5 & 11.4 & 1.4 \\
\hline & $\mathrm{N}_{C}$ & 226.9 & 218.4 & 9.4 & 0.6 \\
\hline 17 & $\mathrm{~N}_{a}$ & 241.6 & 231.9 & 24.4 & 15.6 \\
\hline 18 & $\mathrm{~N}_{a}$ & 249.1 & 240.0 & 28.4 & 19.4 \\
\hline
\end{tabular}

molecule interacting with a selection of compounds from our set, and performing calculations at the B3LYP/6-31 G* level in gas phase and with the PCM aqueous solvation. Considering that water molecules can form HBs with any of the $\mathrm{N}$ or $\mathrm{NH}$ groups present in these molecules, this study was performed to investigate if explicit water molecules can provide a more realistic picture for the solvation influencing the calculated PA/B values. The molecules chosen for this study were: (i) both agonists (1 and 2); (ii) a representative of each Group (2 to 6) (compounds 6, 13, 16, 22 and 24); (iii) a conformationally restricted compound (17); and (iv) a compound with a unique site for protonation (23).

The results presented in Table 7 show similar results with and without an explicit water molecule, and in all cases the same $\mathrm{N}$ atom (usually belonging to a piperidine/piperazine ring or within an aliphatic chain) is preferably protonated.

Inclusion of an explicit water molecule results, as expected, in larger basicities, with an increment of $\sim 7 \mathrm{kcal} \mathrm{mol}^{-1}$ in the gas phase and $\sim 5 \mathrm{kcal} \mathrm{mol}^{-1}$ in the PCM water solvation. In general, the effect of the addition of the water molecule seems to be independent on the compound studied. Our results indicate that the influence of an explicit water molecule confirms the findings obtained with the PCM solvation model alone and, clearly, this added water molecule provides extra stabilization to the protonated system helping provide a better description of the protonation state of these $\alpha 1-A R$ ligands. However, taking into account computational time issues, we can conclude that the 
Table 5. Calculated proton affinities and basicities $\left(\mathrm{kcal} \mathrm{mol}^{-1}\right)$ of Group 5 compound

\begin{tabular}{cccccc} 
& \multicolumn{2}{c}{ Gas phase } & \multicolumn{2}{c}{ PCM (water) } \\
\hline & Nitrogen & PA (0 K) & PA (298 K) & B (0 K) & B (298 K) \\
\hline $\mathbf{1 9}$ & $\mathrm{N}_{a}$ & 250.3 & 240.3 & 25.2 & 14.8 \\
$\mathbf{2 0}$ & $\mathrm{N}_{a}$ & 252.1 & 241.3 & 26.0 & 19.7 \\
& $\mathrm{~N}_{b}$ & 234.7 & 223.8 & 17.3 & 8.6 \\
$\mathbf{2 1}$ & $\mathrm{N}_{a}$ & 247.3 & 237.5 & 24.1 & 14.8 \\
$\mathbf{2 2}$ & $\mathrm{N}_{a}$ & 258.4 & 247.0 & 30.4 & 20.0 \\
$\mathbf{2 3}$ & $\mathrm{N}_{a}$ & 249.0 & 239.9 & 22.7 & 11.1 \\
& & & & &
\end{tabular}

Table 6. Calculated proton affinities and basicities $\left(\mathrm{kcal} \mathrm{mol}^{-1}\right)$ of Group 6 compounds

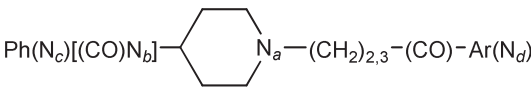

\begin{tabular}{|cccccc|}
\hline & & \multicolumn{2}{c}{ Gas phase } & \multicolumn{2}{c|}{ PCM (water) } \\
& Nitrogen & PA (0 K) & PA (298 K) & B (0 K) & B (298 K) \\
\hline $\mathbf{2 4}$ & $\mathrm{N}_{a}$ & 256.0 & 245.4 & 30.1 & 19.7 \\
& $\mathrm{~N}_{C}$ & 237.0 & 226.8 & 16.4 & 5.9 \\
$\mathbf{2 5}$ & $\mathrm{N}_{a}$ & 246.3 & 238.0 & 27.5 & 16.8 \\
$\mathbf{2 6}$ & $\mathrm{N}_{a}$ & 259.3 & 250.0 & 31.5 & 21.2 \\
\hline & & & & \\
\end{tabular}

Table 7. Calculated proton affinities and basicities $\left(\mathrm{kcal} \mathrm{mol}^{-1}\right)$ using an explicit water molecule

\begin{tabular}{|c|c|c|c|c|c|}
\hline & \multirow[b]{2}{*}{ Nitrogen } & \multicolumn{2}{|c|}{ Gas phase $+\mathrm{H}_{2} \mathrm{O}$} & \multicolumn{2}{|c|}{ PCM (water) + $\mathrm{H}_{2} \mathrm{O}$} \\
\hline & & PA (O K) & PA (298 K) & B (O K) & B $(298 \mathrm{~K})$ \\
\hline 1 & $\mathrm{~N}_{a}$ & 248.1 & 241.9 & 28.9 & 23.1 \\
\hline 2 & $\mathrm{~N}_{a}$ & 244.4 & 237.8 & 28.5 & 22.3 \\
\hline \multirow[t]{3}{*}{6} & $N_{b}$ & 252.8 & 245.0 & 24.3 & 14.8 \\
\hline & $\mathrm{N}_{C}$ & 260.0 & 252.9 & 29.1 & 22.3 \\
\hline & $\mathrm{N}_{d}$ & 253.4 & 245.8 & 19.7 & 9.2 \\
\hline \multirow[t]{3}{*}{13} & $\mathrm{~N}_{a}$ & 259.6 & 251.2 & 25.3 & 16.2 \\
\hline & $N_{b}$ & 268.8 & 255.5 & 27.6 & 18.2 \\
\hline & $\mathrm{N}_{e}$ & 245.6 & 238.0 & 20.5 & 11.2 \\
\hline \multirow[t]{3}{*}{16} & $\mathrm{~N}_{a}$ & 259.5 & 253.4 & 33.8 & 28.4 \\
\hline & $\mathrm{N}_{b}$ & 248.6 & 236.9 & 19.2 & 8.7 \\
\hline & $\mathrm{N}_{C}$ & 227.8 & 222.1 & 13.3 & 5.3 \\
\hline 17 & $\mathrm{~N}_{a}$ & 251.3 & 243.0 & 27.5 & 20.0 \\
\hline 22 & $\mathrm{~N}_{a}$ & 262.2 & 253.7 & 31.7 & 19.8 \\
\hline 23 & $\mathrm{~N}_{a}$ & 256.2 & 247.7 & 27.6 & 19.4 \\
\hline \multirow[t]{2}{*}{24} & $\mathrm{~N}_{a}$ & 261.2 & 250.7 & 30.6 & 19.6 \\
\hline & $\mathrm{N}_{C}$ & 247.2 & 239.0 & 20.7 & 12.2 \\
\hline
\end{tabular}


use of the PCM alone is enough to achieve a good description of such protonated species.

\section{Determination of the $\mathrm{p} K_{\mathrm{a}}$ of the compounds studied}

The basicity of the ligands and their $p K_{\mathrm{a}}$ are critical when analyzing ligand-receptor interactions because basicity determines the interaction with the receptor and the pharmacokinetic properties of the ligand. Considering that the overall proportion of nonionizable/ ionizable compounds for drug-like substances is not well known, Manallack reviewed the literature with regard to both the proportion of ionizable substances and $\mathrm{p} K_{\mathrm{a}}$ distributions. ${ }^{[34]}$ However, the experimental determination of the $\mathrm{p} K_{\mathrm{a}}$ is not always straightforward and there are computational alternatives to predict this parameter. Several commercial packages include an option to evaluate $\mathrm{p} K_{\mathrm{a}}$; however, these packages work as a black box and the methodology used is not always clearly explained. Our approach involves applying the thermodynamic cycle presented in Fig. 1. To validate this theoretical approach, we have computed, first, the $\mathrm{p} K_{\mathrm{a}}$ values of a number of compounds for which an experimental $\mathrm{p} K_{\mathrm{a}}$ had been previously determined (Table 8 ). These compounds include adrenaline (1), noradrenaline (2) and compounds $\mathbf{3}$ to $\mathbf{6}$, which are currently commercially available $\alpha_{1}$-adrenoceptor antagonists and, hence, their $\mathrm{p} K_{\mathrm{a}}$ values are in agreement with the pharmacokinetic properties required for an actual drug. However, because these six values fall within a narrow range (see Table 8), we have also calculated the $p K_{\mathrm{a}}$ value of two compounds, debrisoquin and phenothiazine (Fig. 5), where experimental $\mathrm{p} K_{\mathrm{a}}$ values are very large $\left(11.9^{[35]}\right)$ and very small $\left(2.9^{[35]}\right)$, respectively.

Table 8. Experimental and computational $\mathrm{p} K_{\mathrm{a}}$ values obtained for compounds $\mathbf{1}$ to $\mathbf{6}$ and for reference compounds debrisoquin and phenothiazine

\begin{tabular}{|lcc|} 
& Experimental $\mathrm{p} K_{\mathrm{a}}$ & Computational $\mathrm{p} K_{\mathrm{a}}$ \\
\hline $\mathbf{1}$ & $8.6^{[24]}$ & 9.7 \\
$\mathbf{2}$ & $8.6^{[25]}$ & 9.0 \\
$\mathbf{3}$ & $7.0^{[26]}$ & 8.8 \\
$\mathbf{4}$ & $8.1^{[27]}$ & 8.3 \\
$\mathbf{5}$ & $6.9^{[28]}$ & 7.9 \\
$\mathbf{6}$ & $7.1^{[29]}$ & 8.1 \\
Debrisoquin & $11.9^{[35]}$ & 20.6 \\
Phenothiazine & $2.5^{[35]}$ & -5.9 \\
\hline
\end{tabular}

Debrisoquin is an antihypertensive drug and phenothiazine is present in different neuroleptic and antihistaminic drugs, such as chlorpromazine and promethazine, respectively. These compounds, even though not related to our data set in terms of biological activity, can expand the scope of the computational method because of the extreme $p K_{\mathrm{a}}$ values that they exhibit.

In the case of debrisoquin, the results (Table 8) are in agreement with the experimental $\mathrm{p} K_{\mathrm{a}}$ showing that the guanidine moiety $\left[\mathrm{NH}_{2}-\mathrm{C}(=\mathrm{NH})-\mathrm{N}-\right]$ is a very strong base. This is well known, because guanidine itself is a very strong base in water (exp. $\mathrm{p} K_{\mathrm{a}}=13.6$ ). ${ }^{[36]}$ Regarding phenothiazine, the small calculated $\mathrm{p} K_{\mathrm{a}}$ (Table 8) indicates that the amino group in this compound is weakly basic. Therefore, even though a very large value was calculated for debrisoquin and a very low one was computed for phenothiazine, large deviations from the experimental $\mathrm{p} K_{\mathrm{a}}$ were obtained. However, for those values in the middle range, in general, the computed $\mathrm{p} K_{\mathrm{a}}$ were slightly larger than the experimental ones but they are more or less within the experimental range (see graph in Fig. 5).

Considering that using this theoretical method, acceptable $\mathrm{p} K_{\mathrm{a}}$ values were obtained for the compounds with values in the middle range, the $\mathrm{p} K_{\mathrm{a}}$ value of all the compounds in the dataset was determined in a similar manner. The results (Table 9) indicate that the compounds will be mostly protonated at physiological $\mathrm{pH}$, with most compounds showing $\mathrm{p} K_{\mathrm{a}}$ values larger than 7.

In Group 2, the $\mathrm{p} K_{\mathrm{a}}$ of most of the compounds are within a 7.9 to 9.0 range, except for compounds 8 and $\mathbf{9}$, which $\mathrm{p} K_{\mathrm{a}}$ are $>10$ (Table 9). This can be explained because these two compounds contain a quinoline core instead of a quinazoline core, which is present in the other compounds of the group (3-7). The $p K_{a}$ of quinoline $\left(4.85^{[37]}\right)$ is known to be larger than that of quinazoline $\left(3.31^{[29]}\right)$. Moreover, the $\mathrm{p} K_{\mathrm{a}}$ of pyridine, which is larger than that of pyrimidine (5.14 and 1.10 , respectively $\left.{ }^{[29]}\right)$, becomes even larger with a $\mathrm{NH}_{2}$ group in para (9.17 for 4-aminopyridine ${ }^{[38]}$ vs 5.71 for 4 -aminopyrimidine $e^{[39]}$ ), and all the compounds in this Group 2 have an amino functionality in position 4 of the quinoline/quinazoline cores.

Regarding Group 3, most of the $\mathrm{p} K_{\mathrm{a}}$ values obtained (Table 9) are consistent with this type of $N, N^{\prime}$-arylalkylpiperazines. The $\mathrm{p} K_{\mathrm{a}}$ value of 1-phenylpiperazine is 6.30 and the average $\mathrm{p} K_{\mathrm{a}}$ values for a number of 1-arylpiperazines such as ofloxacin, enoxacin, norfloxacin, ciprofloxacin or pipemidic acid is around 5.6. ${ }^{[40]}$ To explain the low $p K_{\mathrm{a}}$ values of 10, 11 and 15, it should be considered that, when protonated in the piperazine $\mathrm{N}$-alkyl

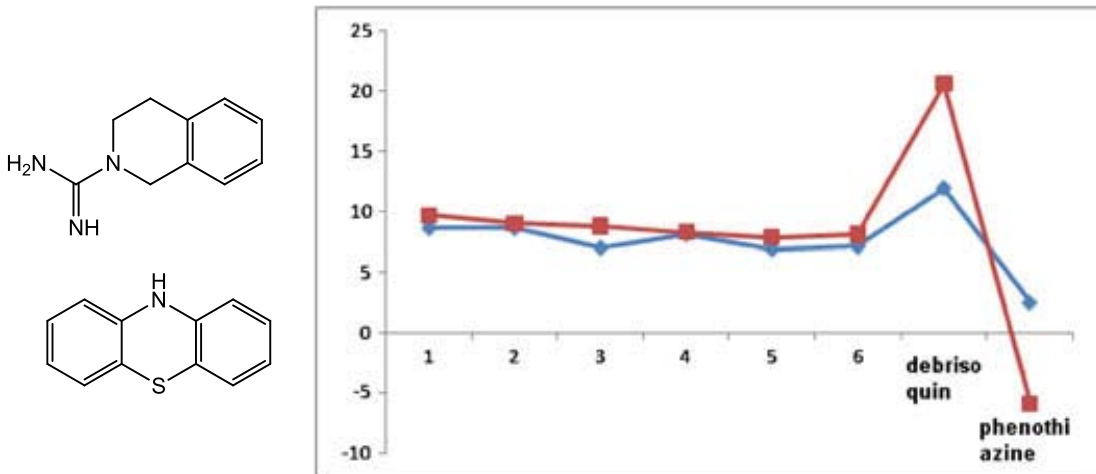

Figure 5. Structure of debrisoquin (left, top) and phenothiazine (left, down) and comparison between experimental (blue) and theoretical (red) $\mathrm{p} K_{\mathrm{a}}$ values. 
Table 9. Calculated $\mathrm{p} K_{\mathrm{a}}$ values from the thermally corrected $B$ values of all the compounds studied here

\begin{tabular}{|c|c|c|c|}
\hline Compound & $\mathrm{p} K_{\mathrm{a}}$ & Compound & $\mathrm{p} K_{\mathrm{a}}$ \\
\hline \multicolumn{2}{|c|}{ Group 1} & \multicolumn{2}{|c|}{ Group 2} \\
\hline 1 & 9.7 & 3 & 8.8 \\
\hline 2 & 9.0 & 4 & 8.3 \\
\hline Gro & & 5 & 7.9 \\
\hline 10 & 6.3 & 6 & 8.1 \\
\hline 11 & 4.2 & 7 & 9.0 \\
\hline 12 & 7.6 & 8 & 11.8 \\
\hline 13 & 6.7 & 9 & 12.2 \\
\hline 14 & 8.0 & \multicolumn{2}{|c|}{ Group 4} \\
\hline 15 & 5.0 & 16 & -3.0 \\
\hline Gro & & 17 & 6.8 \\
\hline 19 & 6.2 & 18 & 9.7 \\
\hline 20 & 9.9 & \multicolumn{2}{|c|}{ Group 6} \\
\hline 21 & 6.3 & 24 & 9.9 \\
\hline 22 & 10.0 & 25 & 7.7 \\
\hline 23 & 3.6 & 26 & 10.9 \\
\hline
\end{tabular}

position, they are able to form intramolecular $\mathrm{HBs}$ with the $\mathrm{O}$ atom of an amide group connected by an ethylene linker (10 in Fig. 6, and 11) or with the $\pi$ system of a double bond ${ }^{[41]}$ (15 in Fig. 6). This intramolecular HB could stabilise the protonated species. Compounds 12, 13 and 14 ( $\mathrm{p} K_{\mathrm{a}} \sim 7$ or more) in their protonated $\mathrm{N}-\mathrm{H}^{+}$form cannot establish such an $\mathrm{HB}$ interaction (i.e. compound $\mathbf{1 2}$ in Fig. 5) and therefore their protonated species are less stabilised.

Compounds 17 and 18, in Group 4, show $\mathrm{p} K_{\mathrm{a}}$ values around 7 or more (Table 9) in agreement with aliphatic tertiary amines. ${ }^{[29]}$ In the case of the $\mathrm{N}$-substituted diphenylamine $\mathbf{1 6}$, the $\mathrm{p} K_{\mathrm{a}}$ obtained is negative in agreement with the low experimental values reported for diphenylamine itself $(0.78)$, $\mathrm{N}$-methyldiphenylamine (1.71), 4-carboxydiphenylamine (-1.24) or 4-nitrodiphenylamine $(-2.78){ }^{[42]}$

The $\mathrm{p} K_{a}$ obtained for compounds in Group 5, can be discussed in three sets even though they all contain an aliphatic amine (secondary or tertiary). Derivatives 19 and $\mathbf{2 1}$ both have two $\mathrm{OCH}_{3}$ groups attached to the phenyl ring at the ortho positions of the $\mathrm{O}$-alkyl chain containing the amine to be protonated (see Fig. 2). In both cases, an HB seems to be formed between the $\mathrm{NH}$ group in the aliphatic chain and one of these $\mathrm{OCH}_{3}$ in the neutral forms $(\mathrm{d}[\mathrm{O} \ldots \mathrm{H}]$ for 19: $2.18 \AA$ and for 21: $2.27 \AA)$. When the amino group is protonated, this HB becomes shorter (d $[\mathrm{O} \ldots \mathrm{H}]$ for 19: 1.81 $\AA$ and for 21: $1.85 \AA$ ), stabilising the cationic species and thus explaining the low $\mathrm{p} K_{\mathrm{a}}$ values obtained (see Table 9). However, this HB is not formed in compounds $\mathbf{2 0}$ and 22 because of the large size of the substituents at the ortho position of the aromatic ring $\left(\mathrm{OCH}_{2} \mathrm{CF}_{3}\right.$ and $\left.\mathrm{OCH}_{2}-\mathrm{Cyclopropane}\right)$. In the case of 23, the $\mathrm{O}$-alkyl chain does not have $\mathrm{OCH}_{3}$ groups in ortho positions in the phenyl ring; however, at the end of the $\mathrm{O}$-alkyl chain there is another aromatic ring containing an ortho $\mathrm{OCH}_{3}$ group. The $\mathrm{N}$ atom to be protonated is a tertiary amine and thus in the neutral form no HB can be form. When the tertiary amine is protonated, though, an $\mathrm{HB}$ is formed between this $\mathrm{NH}+$ group and the $\mathrm{OCH}_{3}$ of the nearest aromatic ring $(\mathrm{d}[\mathrm{O} \ldots \mathrm{H}]$ : $1.91 \AA$ ) forming a pseudo six-membered ring, stabilizing this protonated species and justifying the very low $\mathrm{p} K_{\mathrm{a}}$ value computed.

Finally, the values obtained for the three compounds in Group 6 , which are all $N$-alkylpiperidines, are in the range of experimental $\mathrm{p} K_{\mathrm{a}}$ of related compounds such as 1-propylpiperidine $\left(10.48^{[29]}\right)$.

In general, and considering the results found for debrisoquin and phenothiazine (compounds with extreme $\mathrm{p} K_{\mathrm{a}}$ values), the method seems to work properly only in the middle range (from 6 to $9 \mathrm{p} K_{\mathrm{a}}$ units) and, thus, those computed values obtained outside the middle range (compounds $8,9,11,15,16,22,23,26$ ) should be considered only in qualitative terms.

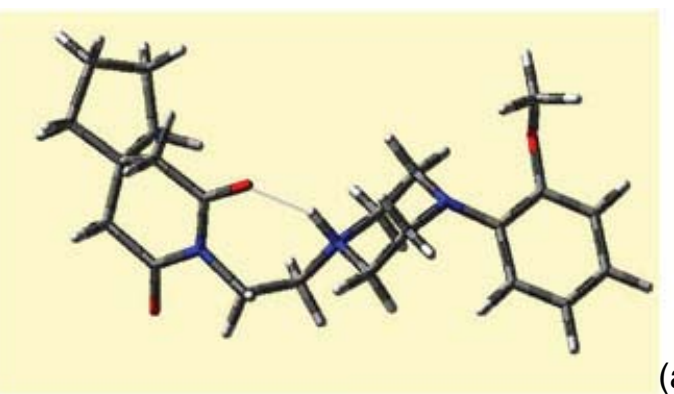

(a)

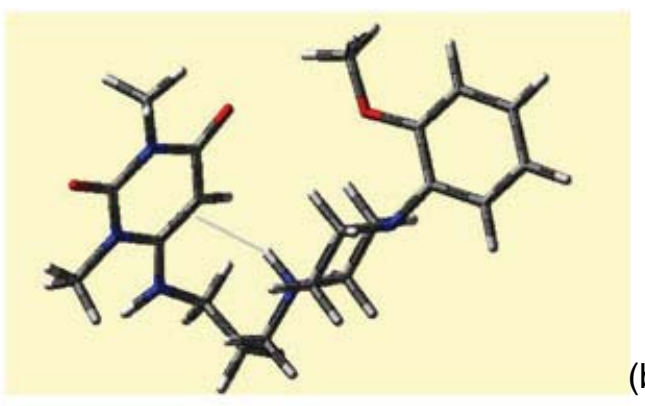

(b)

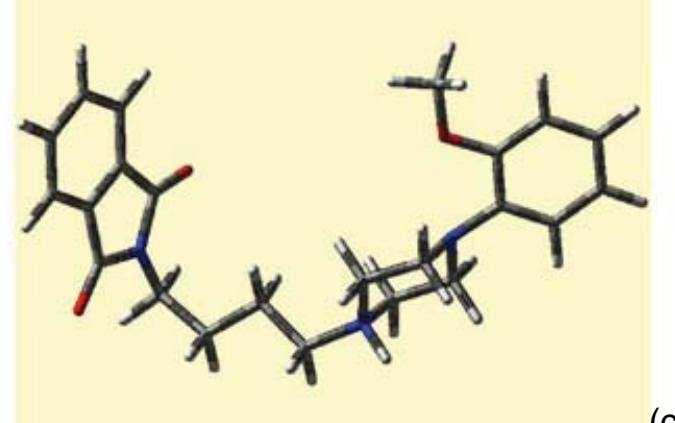

(c)

Figure 6. Optimised structures of the protonated forms of compounds (a) 10, (b) 15 and (c) 12, calculated at B3LYP/6-31 G* level with the PCM solvation model approach, showing the possible $\mathrm{HB}$ formation (grey line) in the case of compounds $\mathbf{1 0}$ (between the $\mathrm{N}-\mathrm{H}^{+}$and a $\mathrm{C}=\mathrm{O}$ of a ring) and $\mathbf{1 5}$ (between the $\mathrm{N}-\mathrm{H}^{+}$and a $\mathrm{C}=\mathrm{C}$ of a ring), and the lack of such a $\mathrm{HB}$ in $\mathbf{1 2}$. 


\section{CONCLUSIONS}

We have performed an extensive conformational search and optimisation to find the optimal minimum energy conformation of a series of $26 \alpha_{1}$-AR ligands (two agonists and 24 antagonists). For each compound a conformational search followed by a semiempirical optimisation was carried out and then, for each ligand, some of these conformations were subjected to further optimisation using DFT methods.

The determination of the proton affinities and basicities of these compounds shows in very few cases different results between optimisation in gas phase or using the PCM solvent model. Because of the fact that compounds interacting with a receptor are normally in an aqueous environment, the basicity values obtained (using the PCM) are of more biological interest than the PAs.

Consistent results are obtained regarding the preferred $\mathrm{N}$ atom for protonation according to the PA/Bs within each group of compounds. This suggests that when structurally similar compounds are studied, their site for protonation can be determined by exploring only a small number of compounds within the set.

To improve the solvation model for our molecules, we have studied the effect that an explicit water molecule would have in the solvation effects. We have found that the addition of an explicit water molecule to our models results in similar results for PA and basicity. The same $\mathrm{N}$ atom was preferred for protonation with or without the explicit water molecule. Therefore, this approach, which is longer in computational time, does not provide any improvement to the determination of PA and/or B.

The interaction between a drug and its receptor at physiological $\mathrm{pH}$ is determined by the $\mathrm{p} K_{\mathrm{a}}$ of the drug. Thus, computational tools that allow for the theoretical determination of the $\mathrm{p} K_{\mathrm{a}}$ have been developed and, by using this type of approximation, we have computationally evaluated the $\mathrm{p} K_{\mathrm{a}}$ values of our set of molecules and those of two reference drugs (debrisoquin and phenothiazine) with extreme $\mathrm{p} K_{\mathrm{a}}$ values (very large and very small $\mathrm{p} K_{\mathrm{a}}$ respectively). The results in this evaluation produced a very large $\mathrm{p} K_{\mathrm{a}}$ for debrisoquin and a very small one for phenothiazine but with very large deviations from the experimental values. However, better agreement was found for those compounds with experimental $\mathrm{p} K_{\mathrm{a}}$ values in the middle range (compounds 1 to 6). Hence, for those compounds with no experimental $\mathrm{p} K_{a}$ values available, the results obtained could be explained based on similar derivatives reported in the literature. Even though the approach seems to work better for $\mathrm{p} K_{\mathrm{a}}$ values in the middle range, it can be used in a qualitative manner outside this range.

\section{Acknowledgement}

This work was funded by a postgraduate studentship from the University of Dublin and by the HEA under the IITAC-PRTLI (Cycle III) grant. All calculations were performed on the IITAC cluster maintained by the Trinity Centre for High Performance Computing (Ireland) and on the CTI belonging to the CSIC (Spain).

\section{REFERENCES}

[1] B. Civantos Calzada, A. Aleixandre de Artiñano, Pharmacol. Res. 2001, 44, 195 .

[2] J. B. Bremner, B. Coban, R. Griffith, K. M. Groenewoud, B. F. Yates, Bioorg. Med. Chem. 2000, 8, 201.

[3] R. Barbaro, L. Betti, M. Botta, F. Corelli, G. Giannaccini, L. Maccari, F. Manetti, G. Strappaghetti, S. Corsano, J. Med. Chem. 2001, 44, 2118
[5] M. Li, K. Tsai, L. Xia, Bioorg. Med. Chem, 2005, 15, 657.

[6] A. Evers, T. Klabunde, J. Med. Chem. 2005, 48, 1088

[7] R. D. Kinser, G. Nicol, D. P. Ridge, J. Phys. Chem. A. 2002, 106, 9925.

[8] O. Schroeder, E. J. Andriole, K. L. Carver, K. E. Colyer, J. C. Poutsma, J. Phys. Chem. A 2004, 108, 326.

[9] I. Alkorta, I. Rozas, O. Mó, M. Yañez, J. Elguero, J. Phys. Chem. A 2001, 105, 7481.

[10] I. Alkorta, I. Rozas, J. Elguero, Theor. Chem. Account 2007, 118, 533.

[11] I. Alkorta, J. Elguero, Tetrahedon 1997, 53, 9741.

[12] J. L. M. Abboud, C. Foces-Foces, R. Notario, R. E. Trifonov, A. P. Volovodenko, V. A. Ostrovskii, I. Alkorta, J. Elguero, Eur. J. Org. Chem. 2001, 3013.

[13] I. Alkorta, O. Picazo, ARKIVOC 2005, ix, 305.

[14] O. Dmitrenko, C. Thorpe, R. D. Bach, J. Phys. Chem. B 2003, 107, 13229.

[15] O. Dmitrenko, C. Thorpe, R. D. Bach, J. Org. Chem. 2007, 26, 8298.

[16] G. K. Kinsella, G. W. Watson, I. Rozas, Bioorg. Med. Chem. 2006, 14, 1580

[17] G. K. Kinsella, F. Rodriguez, G. W. Watson, I. Rozas, Bioorg. Med. Chem. 2007, 15, 2850.

[18] D. M. Camaioni, C. A. Schwerdtfeger, J. Phys. Chem. A. 2005, 109, 10795

[19] C. P. Kelly, C. J. Cramer, D.G. Truhlar, J. Phys. Chem. B 2006, 110, 16066.

[20] T. N. Brown, N. Mora-Diez, J. Phys. Chem. B 2006, 110, 9270.

[21] M. D. Liptak, K. C. Gross, P. G. Seybold, S. Feldbus, G. C. Shields, J. Am Chem. Soc. 2002, 124, 6421.

[22] J. R. Pliego, J. M. Riveros, J. Phys. Chem. A 2002, 106, 7434

[23] X. Lopez, M. Schaefer, A. Dejaegere, M. Karplus, J. Am. Chem. Soc 2002, 124, 5010.

[24] C. Hansch, A. J. Leo, Mechem Project Issue No.26, Pomona College, Claremont, CA.

[25] D. D. Perrin, Dissociation Constants of Organic Bases in Aqueous Solution (compiled for IUPAC) Butterworths, London, 1965.

[26] Pfizer Global Pharmaceuticals (Internal Communication).

[27] Merck Index - an Encyclopaedia of chemicals, drugs and biologicals, 13th edn, M. J. O'Neil, Merck \& Co., Inc., Whitehouse Station, NJ, 2001.

[28] P. G. Strange, Trends Pharmacol. Sci. 1996, 17, 238.

[29] Data on file, Abbott Laboratories scientific Report PPRd/86/238, 10.

[30] Sybyl 7.2, Molecular Modelling system. Tripos Associates: St. Louis, MO.

[31] Gaussian 03, Revision C.02, M. J. Frisch, G. W. Trucks, H. B. Schlegel, G. E. Scuseria, M. A. Robb, J. R. Cheeseman, J. A. Montgomery, T. Vreven, Jr., K. N. Kudin, J. C. Burant, J. M. Millam, S. S. Iyengar, J. Tomasi, V. Barone, B. Mennucci, M. Cossi, G. Scalmani, N. Rega, G. A. Petersson, H. Nakatsuji, M. Hada, M. Ehara, K. Toyota, R. Fukuda, J. Hasegawa, M. Ishida, T. Nakajima, Y. Honda, O. Kitao, H. Nakai, M. Klene, X. Li, J. E. Knox, H. P. Hratchian, J. B. Cross, V. Bakken, C. Adamo, J. Jaramillo, R. Gomperts, R. E. Stratmann, O. Yazyev, A. J. Austin, R. Cammi, C. Pomelli, J. W. Ochterski, P. Y. Ayala, K. Morokuma, G. A. Voth, P. Salvador, J. J. Dannenberg, V. G. Zakrzewski, S. Dapprich, A. D. Daniels, M. C. Strain, O. Farkas, D. K. Malick, A. D. Rabuck, K. Raghavachari, J. B. Foresman, J. V. Ortiz, Q. Cui, A. G. Baboul, S. Clifford, J. Cioslowski, B. B. Stefanov, G. Liu, A. Liashenko, P. Piskorz, I. Komaromi, R. L. Martin, D. J. Fox, T. Keith, M. A. Al-Laham, C. Y. Peng, A. Nanayakkara, M. Challacombe, P. M. W. Gill, B. Johnson, W. Chen, M. W. Wong, C. Gonzalez, J. A. Pople, Gaussian, Inc., Wallingford CT, 2004.

[32] C. P. Kelly, C. J. Cramer, D. G. Truhlar, J. Phys. Chem. A 2006, 110, 2493.

[33] N. Campillo, I. Alkorta, J. A. Paez, P. Goya, J. Chem. Soc. Perkin Trans. 1998, 2, 1889.

[34] D. T. Manallack, Perspect. Med. Chem. 2007, 1, 25-38.

[35] D. A. Williams, T. L. Lemke. Foye's Principles of Medicinal Chemistry 5th edn, Lippincott, Williams and Wilkins, Philadelphia, 2002. 1070-1079.

[36] A. Albert, R. Goldacre, J. Phillips, J. Chem. Soc. 1948, 2240.

[37] H. C. Brown, D. H. McDaniel, O. Haflinger, F. C. Nachod, in E. A. Braude and F. C. Nachod Determination of Organic Structures by Physical Methods, Academic Press, New York, 1955.

[38] S. J. Angyal, C. L. Angyal, J. Chem. Soc. 1952, 1461.

[39] A. Albert, R. Goldacre, J. Phillips, J. Chem. Soc. 1948, 2240.

[40] C.-E. Lin, Y. Deng, Jr., W.-S. Liao, S.-W. Sun, W.-Y. Lin, C.-C. Chen, J. Chromatogr. A. 2004, 1051, 283; and references therein.

[41] Hydrogen bonds between good hydrogen bond donors such as $\mathrm{OH}$ or $\mathrm{NH}$ and $\pi$ systems such as benzene, ethylene or ethene have been described in the literature. For example: I. Rozas, I. Alkorta, J. Elguero J. Phys. Chem. A 1997, 101, 9457; and references therein

[42] A. N. Pankratov, A. E. Shchavlev, J. Anal. Chem. 2001, 56, 123. 